\title{
A classification for edible Citrus (Rutaceae)
}

\author{
D.J. Mabberley
}

\begin{abstract}
Mabberley, D.J. (Rijksherbarium, University of Leiden, Netherlands and Royal Botanic Gardens, Sydney NSW 2000, Australia) 1997. A classification for edible Citrus (Rutaceae). Telopea 7(2): 167-172. A workable Linnaean classification, taking into account recent chemotaxonomic advances, is proposed for edible citrus fruits currently referred to the genus Citrus. They are accommodated in three species and four hybrid groups. Four names are lectotypified.
\end{abstract}

\section{The species problem in Citrus subg. Citrus}

The taxonomy of the citrus fruits is complicated by hybridity and apomixis, with many stable hybrid lines being accorded species status, so that the number of edible species recognised in the genus Citrus L. (type: C. medica L., the citron) varies from 1 to 162, though Swingle (1944) is widely followed. He recognises 12 species with edible fruits (subg. Citrus) and six without (subg. Papeda (Hassk.) Swingle). The latter subgenus is characterised by its free as opposed to the basally connate stamens seen in subg. Citrus and juice vesicles with acrid oil droplets: in Australia it is familiar in cooking, particularly Thai cuisine, in the 'lime-leaves', kaffir or makrut lime, Citrus hystrix DC., a species with widely flanged petioles and probably native in tropical Asia.

Intensive chemotaxonomic studies (see Scora \& Kumamoto 1983, Scora 1989) indicate that subg. Citrus comprises merely four known allopatric wild species - the tropical (see Jones 1995) C. halimii B.C. Stone (Malay Peninsula and Borneo) and C. maxima (Burm.) Merr. (pomelo, pummelo, SE Asia) and the subtropical C. medica L. (citron) and C. reticulata Blanco (mandarin, tangerine). From enzymatic work it has been shown that from the last three of these and two unknown plants, all commercial edible citrus fruits presently referred to the genus Citrus have been derived through selection and hybridisation (usually unintentional), followed by further selection of 'agamic complexes'.

The major importance of these plants in commercial horticulture (cf. Walters 1961) inflated the taxonomic rank of the complexes, resulting in an increasingly complicated technical nomenclature as new hybrid lines were introduced. This prevailed up until the beginning of the eighteenth century with Tournefort according oranges, citrons and lemons distinct generic rank as Aurantium, Citreum and Limon respectively in 1700. But the morphological distinctions are slight and much of the commercially significant striking degustatory distinction rests on a subtlety, the presence and relative proportions of the two stereoisomers of limonene, one of which is bitter (as in lemon), the other sweet (as in mandarin), resulting in the differing tastes of the flesh and juice.

\section{The origins of the principal commercial citrus}

The wild species are indigenous to the Subhimalayan tract, China and western Malesia but most of our knowledge of them and their hybrids comes from cultivated plants introduced to much of the rest of the world via Europe, where they were first given modern Latin names, which it is therefore necessary to typify. The citron 
reached Europe with Alexander the Great after his Asian campaigns, the Romans later introducing the lemon and the Seville orange (a pomelo-mandarin cross), the Arabs adding lime and pomelo after that. The Portuguese brought the sweet orange (another pomelo-mandarin cross), the mandarin (a wild Chinese species) itself not reaching Europe until 1805. The grapefruit arose in the Caribbean as a hybrid (sweet orange pollen on pomelo). The lemon is also of hybrid origin with citron probably a parent and an unknown plant the other. Crossing strains of lemons gives offspring with characteristics of trees known as C. jambhiri Lush. (rough lemon, often used as a tristeza-resistant rootstock for other citrus; rind rough and bumpy), C. aurantiifolia (Christm.) Swingle (lime, apparently a hybrid with pomelo as one parent and probably a second unrecognised plant as the other) and citron, as well as lemons. Such a range of plants is found around abandoned homesteads in Australia.

\section{The earliest Linnaean names}

In his Species plantarum (1753), Linnaeus united all of the citrus known to him in one genus of two species: Citrus medica L., the citron, with var. limon L., the lemon and C. aurantium L., the orange with var. grandis L., the pomelo, and var. sinensis L., the sweet orange. Miller, a year later, revived the Tournefortian genera, but meantime Pehr Osbeck, a devoted disciple of Linnaeus, had been preparing for publication the diary of his journey to the Far East, where he saw citrus in cultivation in Canton. As Hansen and Fox Maule (1973) have shown, Osbeck and Linnaeus corresponded at length about Osbeck's plants, some of which Linnaeus dealt with in his Species plantarum where he used Osbeck's manuscript names for some of them. In turn, Osbeck, thereby one of the earliest to use Linnaean nomenclature, incorporated Linnaeus's identifications in his book, which appeared as Dagbok Öfwer en Ostindsk Resa (1755); he later made changes to it and these were incorporated in the German edition of 1765 .

Linnaeus was most interested in Osbeck's novelties, but not all of even these were included in his own work, such that several of the new plants were to be first described by Osbeck himself in his book (Merrill 1916), where he dealt with some 500 of the 600 species he had collected. According to the published English translation (p. xiv) of the German edition of his book, Osbeck wrote, 'I kept for my own amusement a journal of every thing worthy of observation during my voyage; for this I gave him [Linnaeus] some descriptions of new plants found in Spain, China, and other places, which were immediately incorporated into that capital botanical work then printing under the title of Species Plantarum, and with which my names of plants agree [my emphasis]'. Indeed the vast majority were given Linnaeus's names and at least one of his own new plants not in Linnaeus's work was 'rechristened' to comply with Linnaeus's authority. This plant was what Osbeck had intended to be Clerodendrum chinense (Labiatae s.l.), its presently accepted name (though not published until 1989), as can be seen from his manuscripts preserved in the Linnean Society of London (Mabberley 1995). However, the plant he had was the 'double' form, its flowers with no reproductive structures to speak of, so that he felt compelled to give it the new generic name Cryptanthus Osbeck to fit Linnaeus's Sexual System based on the numbers of reproductive parts in the flower!

None of the citrus Osbeck saw in China, however, was new and so it is not surprising that no specimens were sent to Linnaeus, whom Osbeck dutifully followed in uniting them in a single genus, but he had each and all of Linnaeus's varieties at species rank, though without precisely pinpointing 'basionyms' in his work (compare the similar treatment of Philip Miller's Gardeners Dictionary binomials (1768) in the International Code of Botanical Nomenclature Art. 32.5, Ex. 7). That, otherwise following Linnaean 
authority so slavishly, he should have used the same and all of the epithets as an unconnected independent notion, stretches credulity too far. His species names, then, as advocated by Swingle (see Swingle 1944), should indeed stand as based on Linnaeus's variety names: $C$. grandis (L.) Osbeck ( $=$ C. maxima), C. sinensis (L.) Osbeck (see below) and C. limon (L.) Osbeck (as 'limonia'; Merrill (1916) points out that Osbeck made a number of other typographical slips elsewhere in his book).

\section{Classification}

From a pragmatic point of view, one which was taken many years ago with bananas, where the major crops are triploid clones, some involving hybridity, it may be preferable to abandon a Linnaean classification and refer to the cultivars merely as, for example, Citrus 'Valencia' (an orange) or 'Dancy' (a tangerine): these can then be arranged in Groups as advocated by the International Code of Nomenclature for Cultivated Plants - 1995 (Art. 4.1), e.g. Citrus 'Valencia' (Sweet Orange Group). Where the history of a particular cultivar is unknown or unclear, as in the case of the 'Meyer' lemon, considered by Swingle (1944) to be an orange-lemon cross but not yet confirmed as such, it is most sensible to refer to it in this way: Citrus 'Meyer'. However, where there is certainty, it is more informative to use a Linnaean system, where species and hybrid names for citrus crops indicate their presumed relationship to wild plants. The oldest name for the hybrid group involving oranges (pomelomandarin crosses) is $C$. $\times$ aurantium $\mathrm{L}$. and that for the wild tangerine (i.e. mandarin) is $C$. reticulata Blanco, so that the examples above become $C$. $\times$ aurantium L. 'Valencia' and C. reticulata Blanco 'Dancy', to which the parenthetical Group can be added.

The bulk of commercial edible citrus presently referred to the genus Citrus can now be accommodated in a Linnaean scheme as set out below.

1. Citrus medica L., Sp. Pl. 2: 782 (1753)

Type: [icon] 'Citreum' Tournefort, Inst. Rei Herb. t. 396 (1700); lectotype, Porter in Reg. Veg. 127: 34 (1993). [Linnaeus refers to his Hort. Cliff., where Tournefort is cited, though this type may need conserving to maintain the use of the name for the citron.]

$\mathrm{N}$ India. The citron; cultivars include 'Etrog' used in the Jewish Feast of the Tabernacles.

Involved in two hybrid taxa:

a. Citrus $\times$ limon (L.) Osbeck, Reise Ostind. China: 250 (1765) as 'limonia', pro sp.; Burm.f., Fl. Indica: 173 (1768), pro sp.

[1. Citrus medica $\times$ ?]

C. medica L. var. limon L., Sp. Pl. 2: 782 (1753).

Type: [icon] 'Limon vulgaris' Ferrarius, Hesperides: 193 (1646); lectotype selected here.

The lemons (held by some earlier authors to be backcrosses between lime and citron, in which case this binomial would cover the limes too); cultivars include 'Eureka'. The limelo is a lime-lemon cross (one of Swingle's 'lemonimes') of no commercial significance.

Note: Linnaeus also cites Bauhin's Pinax, of which Burser material is often considered 'voucher' specimens but his direct reference to Ferrarius's plate, which is undoubtedly the lemon, fixes the identity of this binomial. 
b. Citrus $\times$ jambhiri Lush., Ind. Forester 36: 342 (1910), pro sp.

[1. Citrus medica $\times 3$. Citrus reticulata or $(1 . \times$ ?, i.e. Citrus $x$ limon $) \times 3$.]

Type: not indicated but probably a cultivated plant at Dehra Dun, India (?not preserved).

The rough lemons ('bush lemons' in Australia, 'lemandarins' of Swingle); cultivars apparently include the Otaheite Orange $(C . \times$ aurantium L. [var.] otaitensis Risso \& Poit.), one of the dwarf potted oranges of florists, in which case it would be written Citrus $\times$ jambhiri 'Otaheite', as the cultivar name 'Otaheite' is already in use for it (Swingle 1944: 629).

2. Citrus maxima (Burm.) Merr., Interp. Herb. Amb.: 46, 296 (1917)

Aurantium maximum Burm., Herb. Amb. Actuar. Ind. Univ.: [16 ](1755)

Type: [icon] 'Limo decumanus' Rumphius, Herbarium Amboinense 2: t. 24 f. 2 \& B (1741); holotype, see Scora \& Nicolson in Taxon 35: 592 (1986).

C. $\times$ aurantium L. (pro sp.) var. grandis L., Sp. Pl. 2: 783 (1753); C. grandis (L.) Osbeck, Dagb. Ostind. Resa: 98 (1757); C. × aurantium L. (pro sp.) var. decumana L., Sp. Pl. ed. 2, 2: 1101 (1763) nom. superfl. pro var. grandis

Type: [icon] Sloane, Jamaica 1: 41 t. 12 figs 2 \& 3 (1707), lectotype selected here (see also A.C. Smith, Fl. Vitiensis 3: 522 (1985)); 'typotype': Herb. Sloane 7 f. 115 (BM)

SE Asia. The pomelo (pummelo); cultivars include 'Chandler'.

Involved in two hybrid taxa:

a. Citrus $\times$ aurantiifolia (Christm.) Swingle, J. Washington Acad. Sci. 3: 465 (1913) pro sp., as 'aurantifolia'.

[2. Citrus maxima $\times ?^{*}$ ]

Limonia $\times$ aurantiifolia Christm., Vollst. Pflanzensyst. 1: 618 (1777) pro sp., as 'aurantifolia'.

Type: [icon] 'Limonellus sive Limon Nipis' Rumphius, Herbarium Amboinense 2: t. 29 (1741); lectotype selected by Stone in Dassanayake \& Fosberg, Rev. Handbk. Fl. Ceylon 5: 424 (1985).

The lime. *The putative parent differs from the unknown parent of the lemon; Scora \& Kumamoto (1983) consider there may be three wild species in the lime's ancestry, two of them perhaps from outside subg. Citrus (but see also under C. $\times$ limon above). Cultivars include 'Mexican'.

b. Citrus $\times$ aurantium L., Sp. Pl. 2: 782 (1753), pro sp.

[2. Citrus maxima $\times 3$. Citrus reticulata]

Type: Probably cultivated in Europe, Herb. Linn. 937.2, upper row of leaves; lectotype selected here (LINN).

C. $\times$ aurantium L., pro sp., var. sinensis L., Sp. Pl. 2: 783 (1753); C. $\times$ sinensis (L.) Osbeck, Reise Ostind. China: 250 (1765), pro sp.

Type: Probably cultivated in Europe, Herb. Linn. 937.2, lower row of leaves; lectotype selected here (LINN). The choice of Bauhin s.n. (BAS) by Porter \& Elias, Ann. Missouri Bot. Gard. 66: 132 (1979), apparently unseen, is here considered an unnecessary neotypification. 
C. $\times$ paradisi Macfad. in Hook., Bot. Misc. 1: 304 (1830), pro sp.

Type: not preserved.

Oranges and grapefruits, those of the original hybrids with more features of $C$. maxima being the bitter or Seville oranges (Sour Orange Group), those with more of C. reticulata being the sweet oranges (Sweet Orange Group; C. $\times$ sinensis). The grapefruit (Grapefruit Group; C. $\times$ paradisi) is a backcross between an orange and C. maxima made in Barbados in the eighteenth century; further backcrosses between it and C. maxima are in commerce. Tangors, ortaniques, etc. (Tangor Group; C. $\times$ nobilis Lour., pro sp.) are backcrosses with $C$. reticulata, many of which (?repeated backcrosses) are called mandarins in commerce, though the true mandarin is referable to C. reticulata itself. Tangelos (Tangelo Group; C. $\times$ tangelo J.W. Ingram \& H.E. Moore) are yet further crosses, between grapefruit and C. reticulata; these in turn have been backcrossed with $C$. reticulata to give cultivars such as 'Page'.

The most important group commercially. Cultivars include 'Chinotto' (Sour Orange Group), 'Baia' (the earlier name for 'Washington Navel') introduced to the Sydney Botanic Garden in 1828 (Passos et al. 1978), 'Lane's Late Navel', 'Leng Navel', 'Red Navel', 'Seedless Valencia', 'Shamouti' ('Jaffa') and 'Valencia' (Sweet Orange Group), 'Marsh Seedless' and 'Star Ruby' (Grapefruit Group), 'Honey Murcott' ('Murcott'), 'Wilking' (Tangor Group), 'Minneola' (Tangelo Group).

Note: Coode, Flore des Mascareignes 65: 29 (1979), selected Herb. Linn. 937.2 as lectotype but, as Fawcett \& Rendle, Fl. Jamaica 2: 187 (1920), point out, this sheet bears leaves of both bitter (i.e. var. aurantium L.) and sweet (i.e. var. sinensis L.) oranges. The upper row has the widely winged petioles typical of the type variety, the lower one the narrowly winged petioles of the sweet orange.

3. Citrus reticulata Blanco, Fl. Filip.: 610 (1837)

Type: Philippines: Luzon, Species Blancoanae 402; neotype, selected by Swingle 1944: 413 (UC, n.v.; BM, K).

Subtropical China. Tangerine, mandarin, satsuma, clementine; cultivars include 'Clementine', 'Dancy', 'Emperor', 'Fina', 'Imperial', 'Nova', 'Owari'.

Also in commerce, but for flavouring (oil of bergamot extracted from the peel and used in eau-de-cologne and Earl Grey tea) rather than fresh fruit or juice, is the bergamot sour orange, which Scora (1989) considers to be a citron-orange cross, i.e. C. medica $\times($ C. maxima $\times$ C. reticulata $)$, and according to the above scheme is ' $1 . \times(2 . \times 3 .)^{\prime}$ ', Citrus $\times$ bergamia Risso \& Poit.

\section{Conclusion}

This scheme provides a workable system for botanists and fruit-growers alike. The nature of the variation in the group, however, makes a conventional identification key to any but the wild species impossible to construct. Here are covered all the commercial citrus presently referred to the genus Citrus; those such as calamondins, kumquats and limequats presently referred to allied genera or 'hybrid genera' will be dealt with in a subsequent paper devoted to the relationships of such genera to Citrus itself. 


\section{Acknowledgments}

I am greatly indebted to Charlie Jarvis for help over the typification of the Linnaean names. Alistair Hay and Surrey Jacobs kindly commented on an early draft of the paper.

\section{References}

Hansen, C. \& Fox Maule, A. (1973) Pehr Osbeck's collections and Linnaeus's Species plantarum. Botanical Journal of the Linnean Society 67: 189-212.

Jones, D. T. (1995) Citrus. Pp. 362-369 in Soepadmo, E. \& Wong, K.M. (eds), Tree Flora of Sabah and Sarawak, vol. 1. (Forest Research Institute Malaysia, Sabah Forestry Department, Sarawak Forestry Department: Kuala Lumpur).

Mabberley, D.J. (1995) Plants and prejudice. (Rijksuniversiteit te Leiden: Leiden).

Merrill, E.D. (1916) Osbeck's Dagbok Öfwer en Ostindsk Resa. American Journal of Botany 10: 571-588.

Passos, O.S., Coelho, Y.S \& Cunha Sobrinho, A.P. (1978) The history of the navel orange and its behavior in the state of Bahia, Brazil. Proc. Int. Soc. Citriculture 1977, 2: 645-647.

Scora, R.W. (1989) Biochemistry, taxonomy and evolution of modern cultivated citrus. Proc. Sixth Int. Citrus Cong.: 277-289.

Scora, R.W. \& Kumamoto, J. (1983) Chemotaxonomy of the genus Citrus. Pp. 343-351 in Waterman, P.G. \& Grundon, M.F. (eds), Chemistry and Chemical Taxonomy of the Rutales. (Academic Press: London).

Swingle, W.T. (1944, '1943') The history, botany and breeding. Vol. 1 of Webber, H.J. \& Batchelor, L.D. The Citrus Industry, 3 vols. (University of California Press).

Walters, S.M. (1961) The shaping of angiosperm taxonomy. New Phytologist 60: 74-84.

\section{Manuscript received 12 February 1997 \\ Manuscript accepted 22 May 1997}

